\title{
NOVOS OLHARES SOBRE O ANARQUISMO - UMA ENTREVISTA COM DAVIDE
} TURCATO

\section{NEW PERSPECTIVES ON ANARCHISM - A INTERVIEW WITH DAVIDE TURCATO}

\author{
Clayton Peron Franco de Godoy* \\ Eduardo Souza Cunha**
}

São Paulo, 26 de janeiro de 2018

Davide Turcato é doutor em História pela Simon Fraser University, do Canadá. Em 2009, defendeu a tese "Making sense of anarchism: The Experiments with Revolution of Errico Malatesta, Italian exile in London, 1889-1900”, posteriormente publicada em livro ${ }^{1}$. Ao analisar as ações e os pensamentos de Errico Malatesta no final do século XIX, o autor rompe com a visão do anarquismo como um fenômeno irracional, espontâneo e adepto do "tudo ou nada". Especialista em anarquismo italiano, sua análise da atuação dos militantes ácratas como um movimento transnacional tornou-se paradigmática. Atualmente, ele é o editor responsável pela obras completas de Errico Malatesta, publicada pelas editoras Zero in Condotta, de Milão, e La Fiaccola, de Ragusa. A previsão é de que o conjunto da obra ocupe dez tomos, dos quais três já foram editados.

$\mathrm{Na}$ entrevista a seguir, concedida por e-mail, nosso intuito foi estruturar as questões em três eixos: avaliação da abordagem transnacional adotada na recente historiografia do anarquismo, reflexões metodológicas e tópicos de investigação presentes em suas pesquisas e, por fim, explicações sobre a atualidade do pensamento anarquista de Malatesta e o desenvolvimento do trabalho de resgate de suas obras completas.

\footnotetext{
* Doutor em Sociologia pela Universidade de São Paulo (USP) e pesquisador do Grupo de Pesquisa Poder Político, Educação, Lutas Sociais da Faculdade de Educação da USP (GPEL/FE-USP). E-mail: claytonperon@gmail.com.

** Mestrando em História Econômica pela Universidade de São Paulo (USP) com a pesquisa intitulada "Editar a Revolta: a edição e a circulação de impressos na formação das organizações operárias de Buenos Aires (18901910)", realizada com apoio da FAPESP (n 2015/10523-6, Fundação de Amparo à Pesquisa do Estado de São Paulo. As opiniões, hipóteses e conclusões ou recomendações expressas neste material são de responsabilidade dos autores e não necessariamente refletem a visão da FAPESP). E-mail: eduardoascunha @ gmail.com.

1 TURCATO, Davide. Making Sense of Anarchism: Errico Malatesta's Experiments with Revolution, 18891900. Oakland: AK Press, 2015.
} 
1) Há dez anos você publicou seu trabalho "Anarquismo italiano como um movimento transnacional"2. Desde então, muitos estudos sobre a história do anarquismo adotaram a perspectiva transnacional usando seu trabalho, entre outros, como referência. Qual é a sua avaliação para este conjunto de pesquisas? Qual o progresso alcançado e em que temas e objetos é possível e necessário avançar?

Minha avaliação geral dos estudos transnacionais do anarquismo é certamente positiva. A antiga historiografia do anarquismo sofreu muitas vezes com a armadilha de utilizar métodos adequados para estudar outros movimentos, mas não o anarquismo. Dessa forma, o anarquismo era tido como algo estranho, embora a estranheza estivesse na abordagem historiográfica. A perspectiva transnacional, em conjunto com a visão do anarquismo como uma rede, ajudou a quebrar algumas das barreiras que impediram os historiadores de analisar o anarquismo sob a ótica apropriada. O nacionalismo metodológico é apenas uma dessas barreiras, mas também há barreiras na concepção da relação entre o indivíduo e o coletivo, entre organização formal e informal, entre ação institucional e encoberta. Um partido político nacional é bastante diferente de uma rede transnacional. Se pararmos de igualar a organização com partidos, podemos entender como os anarquistas se organizaram. Por outro lado, se começarmos a olhar para as vidas individuais anarquistas como partes das redes, a imagem tradicional do cavaleiro-errante pode começar a dissolver, emergindo um padrão de interpretação de ação integrada. Ao quebrar essas barreiras, muitos progressos foram feitos no caminho certo. Por onde novos progressos podem avançar? Eu desejo que a abordagem transnacional também se torne mais translinguística. Ainda estamos muito confinados na língua inglesa. A imprensa anarquista foi notavelmente eficaz na circulação de idéias atravessando continentes e línguas. Se cada estudioso é confinado a um par de idiomas, somos como os cegos da antiga parábola indiana - estudamos o elefante anarquista, sentindo apenas uma pequena parte do corpo. Por outro lado, eu também gostaria de ver uma aplicação mais ampla da teoria das redes sociais, como uma ferramenta para entender como a ação coletiva emerge das interações individuais.

\footnotetext{
${ }^{2}$ Ver TURCATO, Davide. Italian Anarchism as a transnational movement, 1885-1915. International Review of Social History, vol. 52, $\mathrm{n}^{\mathrm{o}} 3$ (dec.), p. 407-444, 2007.
} 
2) Entre os diversos estudos transnacionais, existe uma variedade de objetos interpretados de maneiras distintas, tendo como elemento em comum superar o nacionalismo metodológico na investigação do anarquismo. Por exemplo, existem pesquisas que estudam a formação do anarquismo em regiões fronteiriças, as relações transnacionais de uma região específica com o restante do globo ou ainda os vínculos entre anarquistas de uma mesma etnia ou portadores de uma mesma língua que migraram para diferentes países. Além do ponto de partida (isto é, a superação do nacionalismo metodológico) você acha que é possível pensar em outros elementos em comum, sobretudo em termos teóricos e metodológicos, que dão uma unidade a essas pesquisas recentes?

De fato, o transnacionalismo é um guarda-chuva sob o qual coexistem uma ampla gama de abordagens. Talvez, as semelhanças não se encontrem tanto em qualquer suposição metodológica compartilhada, mas em motivações subjacentes em comum. Na minha visão, não considero uma abordagem transnacional - seja qual for o seu significado - como boa em si mesma. Afinal, pode-se usar uma abordagem transnacional para escrever sobre conspirações judias em todo o mundo, mas eu suspeito que isso provavelmente resultaria em uma má historiografia. Para mim, uma abordagem transnacional é um meio - um de vários meios para um fim. O fim é "entender" o anarquismo, no sentido em que a "compreensão" é definida na sociologia interpretativa de Max Weber e Raymond Boudon. Para eles, a compreensão significa fornecer uma explicação racional do comportamento do ator. A este respeito, a substituição do nacionalismo metodológico por uma abordagem transnacional é apenas uma maneira pela qual podemos entender a ação dos anarquistas em face da aparente irracionalidade. Bem, eu diria que esse compromisso com a compreensão dos anarquistas, em contraste com uma longa tradição historiográfica que considerava os anarquistas como irracionais e milenaristas, é o que muitos da onda atual de jovens estudiosos compartilham. Isso é um aspecto mais valioso do que a própria abordagem transnacional.

3) O historiador Marcel van der Linden, outro expoente dos estudos transnacionais, caracteriza a História Global do Trabalho como um campo de interesse onde não apenas 


\section{é possível o pluralismo teórico mas, na realidade, ele é estimulado ${ }^{3}$. Você acredita que a} historiografia transnacional do anarquismo também pode ser caracterizada desse modo ou existe alguma base que lhe confere certa unidade?

Eu certamente concordo que o pluralismo teórico é benéfico, além de ser inevitável. De fato, quanto mais van der Linden define a história global do trabalho, a história transnacional - seja do anarquismo ou de outros movimentos - é ainda mais vagamente definida. Mesmo a rejeição de um quadro nacional de análise precisa ser qualificada. No artigo que você mencionou, van der Linden rejeita o Estado-nação como unidade de análise e defende a sociedade global como o escopo do pesquisador da História do Trabalho. Ao fazê-lo, ele parece reafirmar a equação entre "nação" e "estado" que está implícita no conceito de Estadonação. Ao escrever sobre o anarquismo italiano como um movimento transnacional, minha preocupação era no sentido contrário, isto é, quebrar esse vínculo entre a Nação e o Estado. Meu argumento é que o anarquismo italiano era um movimento com um forte caráter nacional, mas que, para entender o seu funcionamento, precisamos olhar para além das fronteiras do Estado italiano. Penso que a identidade nacional é uma questão importante se queremos entender o anarquismo. Os historiadores têm muitas vezes a tendência de ditar o que os anarquistas podem fazer - e mais frequentemente o que não podem fazer - se quiserem permanecer coerentes: não podem se organizar, não podem lutar por ganhos parciais,e não podem ter uma identidade nacional, com pena de trair seu anarquismo, sua concepção revolucionária e o seu internacionalismo. Parece que a única opção que lhes é deixada como anarquistas é precisamente aquela em que são mais estereotipados, de alguém que sai jogando bombas. Na verdade, todas essas pretensas impossibilidades são, na verdade, o resultado de distorções. Na realidade, nutrir uma identidade nacional não contradiz o anarquismo, desde que seja dentro de um espírito inclusivo e não se transforme em nacionalismo. E a história do anarquismo italiano está lá para mostrar como os anarquistas italianos, da Argentina aos Estados Unidos, do Brasil à Inglaterra e da França ao Egito, tiveram seu olhar voltado para a Itália como foco de atenção.

\footnotetext{
${ }^{3}$ Ver LINDEN, Marcel van Der. Globalizando a Historiografia das Classes Trabalhadoras e dos Movimentos Operários: Alguns Pensamentos Preliminares. Revista Trajetos, vol. 1, no 2 (dez), p.1-14, 2002. Disponível em: <http://www.revistatrajetos.ufc.br/index.php/Trajetos/article/viewFile/51/26>. Acesso em: 28 jan. 2018.
} 
4) Como você definiria atualmente as distinções conceituais entre transnacionalismo e internacionalismo, tanto do ponto de vista teórico-analítico como prático, ou seja, no nível da militância política?

Os conceitos de transnacionalismo e internacionalismo pertencem a diferentes domínios. $\mathrm{O}$ internacionalismo é um conceito normativo: os internacionalistas acreditam que os trabalhadores em todo o mundo devem lutar e viver em fraternidade, sem colocar a sua própria nação acima das demais. O transnacionalismo é um conceito descritivo: descrevemos um movimento, como o movimento anarquista italiano, como transnacional. Bem, também é um conceito metodológico e, por conseguinte, também é normativo, mas é normativo para o historiador, o observador, e não para o ator. Do ponto de vista do militante, penso que a relação entre o internacionalismo e o transnacionalismo é a seguinte: os anarquistas eram internacionalistas, mas viviam em um mundo em que os Estados-Nação eram um fato. Eles se concentraram na luta em seu país natal, onde quer que vivessem no mundo, como uma espécie de divisão do trabalho em sua luta internacionalista em comum com os demais militantes. Mas eles também se envolveram em lutas nacionais de outras localidades. Isto é o que eu chamei de "nacionalismo cruzado". Por exemplo, o russo Stepniak lutou na Itália; o italiano Malatesta realizou uma jornada de conferências na Espanha; e o espanhol Pedro Esteve editou um periódico italiano em Paterson, Nova Jersey, nos Estados Unidos. A este respeito, eles fizeram apenas o que os patriotas como Mazzini e Garibaldi, em suas visões universalistas, tinham feito antes deles, ajudando as lutas de outros povos para a independência nacional. A diferença era que esses patriotas lutaram para estabelecer Estados nacionais, enquanto os anarquistas lutaram para derrubá-los. Ambos valorizaram a diversidade nacional, mas os anarquistas acreditavam que a diversidade não deveria ser cristalizada em Estados exclusivistas.

\section{5) Qual sua avaliação do cenário da ampla e renovada produção e interesse sobre o} anarquismo nas instituições universitárias? Você acredita que isso pode ter que tipos de efeitos intra-acadêmicos e extra-acadêmicos?

É animador ver como os estudos sobre o anarquismo estão crescendo em ambientes acadêmicos. $\mathrm{O}$ anarquismo desloca progressivamente o marxismo como o representante do radicalismo de esquerda. Esta produção intelectual pode ser muito benéfica para o anarquismo 
como movimento, desde que permaneça claro que pesquisadores e militantes operam em diferentes planos. Os pesquisadores são observadores, os militantes são atores. Eles mantêm uma relação diferente com a história do movimento anarquista e com a tradição anarquista. Os militantes promovem e renovam essa tradição nas ruas e nos locais de trabalho, enquanto os pesquisadores, na minha opinião, estudam, esclarecem e explicam essa tradição. Em grande medida, a tradição anarquista ainda é muito mal interpretada e distorcida. Ela é enxergada como sendo intelectualmente empobrecida, enquanto penso que ela é intelectualmente muito rica e sofisticada. Mesmo as muitas derrotas que os anarquistas sofreram não são necessariamente um sinal de sua inadequação, mas sim um sinal da sua consciência de que é crucial permanecer no caminho certo, manter os meios de acordo com os fins, mesmo em caso de derrota. Esta tradição brilhante, se devidamente avaliada, pode realmente se tornar uma poderosa arma cultural no arsenal do movimento anarquista. É tarefa dos pesquisadores forjar essa arma e colocá-la nas mãos dos militantes anarquistas. No entanto, quando certos estudiosos inscrevem toda a tradição anarquista como "anarquismo clássico", incorrendo no pecado intelectual do essencialismo e, desse modo, transformando o anarquismo em um tipo livresco desenvolvido em salões de conferências, eu questionaria tanto a solidez de sua metodologia como o possível benefício que pode surtir para o movimento anarquista.

\section{6) Qual o papel dos militantes anarquistas da América do Norte na rede transnacional do anarquismo italiano entre os anos 1880 e 1914? Na sua perspectiva, havia uma colaboração entre esses militantes e aqueles situados na América do Sul ou a relação privilegiada era com os anarquistas localizados na Europa?}

O papel dos militantes anarquistas na América do Norte foi simplesmente fundamental para o movimento anarquista italiano e isso se estendeu muito além das três décadas que eu discuti em meu artigo sobre o transnacionalismo anarquista italiano ${ }^{4}$. É uma história fascinante. Se eu lhe perguntasse qual é a conexão que existe entre a ocupação de fábricas em 1920 na Itália e os campos de mineração de carvão do Kansas, você provavelmente ficaria encucado. Bem, verifica-se que as contribuições do rude Meio Oeste norte-americano para o jornal anarquista Umanità Nova naquele ano se equiparavam a noventa por cento das contribuições provenientes de toda a Itália. E, é claro, durante o fascismo, os periódicos italianos nos

\footnotetext{
${ }^{4}$ Ver TURCATO, 2007.
} 
Estados Unidos tornaram-se a voz do anarquismo que foi silenciado na terra natal. $\mathrm{O}$ anarquista da América do Norte abriu mesmo seu caminho na história italiana em geral por meio da pessoa de Gaetano Bresci, que veio de Nova Jersey para matar o rei Umberto em 1900. Ainda assim, enquanto a Itália permaneceu como o foco comum dos anarquistas italianos em todo o mundo, especialmente em tempos de repressão na terra natal, as conexões dentro da rede eram multidirecionais. Claro, certos nós estavam mais densamente ligados do que outros, sendo Londres o exemplo mais notável. Londres era a capital não oficial não apenas do movimento anarquista internacional, mas de movimentos revolucionários em geral. No entanto, a rede não tinha um único centro. São Paulo, Buenos Aires, Paterson, Londres, Paris, Tunes, Alexandria, apenas para mencionar alguns, foram todos nós importantes com conexões diretas. Os militantes da América do Sul e do Norte publicavam correspondências dos lugares uns dos outros em seus jornais, reimprimiam mutuamente artigos, trocavam panfletos para venda, enviavam assinaturas etc. Mesmo a mobilidade dos militantes não era necessariamente apenas da e para a Itália, mas frequentemente foi entre países de emigração.

7) Na sua tese de doutorado de 2009 - posteriormente publicada como livro em $2012^{5}$ você analisou as ideias e as ações de Errico Malatesta no período entre 1889 e 1900 . Você investigou a evolução das ideias teóricas, táticas e estratégicas de Malatesta em um período rico do debate interno do anarquismo - temas como a organização, a validade da propaganda pelo fato, a atuação dos anarquistas dentro dos sindicatos, entre outros, estavam presentes. Você poderia nos sintetizar esse contexto e como ele influenciou Malatesta?

Eu escolhi lidar com a década de 1889-1900 porque é central na vida de Malatesta. Ela contém os momentos mais importantes de sua militância de sessenta anos. Ao mesmo tempo, essa década oferece uma janela conveniente na vida transnacional de um grande anarquista, através da qual é fácil ver como sua exposição a uma diversidade de contextos nacionais e lutas dos trabalhadores enriqueceu seus pontos de vista e influenciou suas táticas. Ele testemunhou a greve do porto de Londres (1889), que o deixou consciente do potencial da ação direta em grande escala; o surgimento das agitações do primeiro de maio na França, na Itália e na Espanha; o uso, pelos trabalhadores belgas, da greve geral para fins políticos; e as

\footnotetext{
${ }^{5}$ Ver TURCATO, 2015.
} 
agitações camponesas quase insurrecionais na Sicília. Ele desenvolveu novas idéias sobre o movimento operário em paralelo com seus companheiros sindicalistas franceses exilados em Londres, de modo que, quando ele retornou à Itália em 1897, ele pôde introduzir anarquistas italianos nas novas táticas de ação direta, como boicote e sabotagem, que estavam sendo usado na Grã-Bretanha e na França. Suas opiniões mudaram novamente à luz dos motins do pão de 1898 na Itália e da severa repressão que se seguiu. Nos Estados Unidos, ele debateu a questão da organização entre os anarquistas italianos; envolveu-se nas questões operárias dos trabalhadores de tabaco de língua espanhola; e familiarizou-se com a espinhosa interação da luta de classes e do nacionalismo em Cuba. Tudo isso ilustra como Malatesta e seus companheiros anarquistas não eram esses utopistas ingênuos separados da realidade que alguns historiadores querem que acreditemos. Em vez disso, seu pensamento e ação foram baseados em suas experiências de primeira mão do capitalismo avançado e da luta de classes em diferentes países e continentes. À luz dessas experiências, Malatesta desenvolveu um novo tipo de anarquismo pluralista, experimentalista e gradualista que percorreu um longo caminho desde as perspectivas de seus primeiros anos internacionalistas.

8) Em resposta à historiografia tradicional que caracteriza o anarquismo como um movimento político utópico, que aposta no espontaneísmo das massas e abre mão da organização, em seu trabalho você defende a racionalidade do projeto político anarquista. No caso de Malatesta, você afirma que a evolução do seu pensamento político está baseada em uma metodologia de tentativa e erro, no qual ele fez "experimentos revolucionários". Você poderia falar mais a respeito?

Permita-me tocar rapidamente a questão da racionalidade. Quando defendo a racionalidade dos anarquistas, não quero dizer que isso seja um argumento empírico. Não estou observando o comportamento dos anarquistas e concluindo que era racional. Na verdade, é o contrário. O meu argumento, baseado nas ideias do filósofo americano Donald Davidson, é que a atribuição da racionalidade é uma presunção metodológica e não uma descoberta empírica. Nós sempre podemos interpretar o comportamento das pessoas de muitas maneiras diferentes. O princípio metodológico de Davidson é que devemos presumir que os atores que observamos são racionais e selecionar a interpretação de seu comportamento que maximize a racionalidade. Ele denomina isso de "princípio da caridade": ao interpretar o comportamento de alguém, devemos ser guiados por uma atitude de caridade. Os anarquistas, como objetos de 
estudo histórico, nem sempre desfrutaram de tal atitude. A questão da espontaneidade é um bom exemplo. Quando os anarquistas reivindicam o valor da espontaneidade, são interpretados como se estivessem dizendo disparates, como se estivessem esperando que cada um se ocupasse com seus próprios negócios e a sociedade funcionasse perfeitamente, como que por magia. No entanto, nossa sociedade capitalista baseia-se em um processo essencialmente espontâneo (pelo menos de acordo com os livros didáticos), o mercado, mas ninguém questiona isso. Na verdade, a defesa anarquista da espontaneidade tem pouco a ver com a harmonia natural. Pelo contrário, é uma rejeição da engenharia social. Isso significa que ninguém pode desenhar um modelo da sociedade. Os melhores arranjos sociais devem surgir do método da liberdade, da experimentação. Isso me leva à sua pergunta. Na verdade, a palavra "experiência" e seus derivados são muito importantes em Malatesta. Um sentido em que o termo é importante é o que acabei de explicar. Como disse Malatesta, os ideais anarquistas são "o sistema experimental trazido do campo de pesquisa para o da realização social". O outro sentido é o que eu queria transmitir no título do meu livro, quando referi-me aos "experimentos de Malatesta com a revolução". Parte da grandeza de Malatesta é que ele sempre aprendeu a lição de experiência e ajustou suas táticas de acordo com isso. Os eventos que mencionei, a greve do porto de Londres, a derrota do movimento Fasci Siciliani (1894), os motins do pão de 1898, foram todas oportunidades para Malatesta analisar as derrotas dos anarquistas e formular alterações táticas. Ele nunca somente falou sobre a revolução. Ele realmente queria e esforçou-se para fazer uma.

9) Atualmente, você está organizando as obras completas de Malatesta, que estão sendo publicadas pela editora Zero in Condotta, de Milão. Você poderia explicar mais detalhadamente essa iniciativa, sua motivação e finalidade?

As obras completas da Malatesta são, na verdade, um esforço conjunto de dois editores, Zero in Condotta em Milão e La Fiaccola em Ragusa. Este é um projeto com uma longa história. Foi iniciado na década de 1930 pelos amigos e camaradas da Malatesta, Luigi Fabbri e Luigi Bertoni, mas eles conseguiram publicar apenas três volumes. Um dia, há muitos anos atrás, eu casualmente li o plano de Fabbri para todo o projeto e disse para mim mesmo que merecia ser completado. Então eu comecei a trabalhar nisso. Uma forte motivação me veio da leitura desses três volumes, porque me fizeram perceber o quanto mais existe nos escritos de Malatesta do que se pode obter de uma antologia. A maioria dos escritos de Malatesta são 
artigos escritos na imprensa anarquista em resposta a eventos do dia-a-dia ocorridos nos movimentos anarquistas e operários. No entanto, cada artigo repercute em nós, por causa da habilidade de Malatesta de destacar um aspecto abrangente de um evento pequeno, contingente. Há uma profundidade de pensamento que se estende muito além do evento particular que ocasionou o artigo. Uma razão correlata por que eu acho importante ler as obras completas de Malatesta é que, precisamente porque seus artigos costumavam ser escritos em resposta a eventos contingentes, é fácil fazer com que Malatesta diga o que se quer tomando um ou outro de seus artigos isoladamente. Malatesta foi muitas vezes impelido pela preocupação de retificar um ou outro exagero entre os anarquistas, e, portanto, em artigos diferentes, ele poderia enfatizar o lado diferente da mesma questão. É somente lendo todos os artigos sobre um determinado tópico em conjunto que se tem a ideia exata e se compreende a profunda coerência do pensamento de Malatesta. Finalmente, os trabalhos completos põem em evidência a evolução do pensamento de Malatesta, o que é facilmente perdido em antologias. Como eu disse antes, Malatesta aprendeu pela experiência e ajustou suas táticas em conformidade a isso. É somente ao ler seus escritos em ordem cronológica que se aprecia plenamente o pragmatismo de Malatesta na adaptação de suas táticas em resposta a erros passados e novas condições.

\section{0) Para você, o resgate do pensamento e da ação de Malatesta pode dar que tipo de} contribuição teórica e prática ao anarquismo atualmente?

Deixe-me ser contundente: acho que Malatesta definiu o anarquismo para nós. Se você pedir a alguém para definir o anarquismo, você provavelmente receberá uma resposta que é inadequada ou vaga até o ponto de ser inútil. Muitos provavelmente se recusarão a responder com o argumento de que existem muitos "anarquismos". Bem, acho que o trabalho de Malatesta fornece essa resposta com uma clareza e uma profundidade que permanecem insuperáveis. Por exemplo, no seu panfleto Anarquia ${ }^{6}$ há uma breve definição que eu amo porque simboliza essa união de simplicidade e profundidade: "A anarquia - ele escreve - tem como base, como seu ponto de partida, como seu ambiente essencial, a igualdade de condições; seu farol é a solidariedade e a liberdade é o seu método". Parece uma definição trivial, mas resume uma visão completa do anarquismo, ponderada e original. Nesta

\footnotetext{
${ }^{6}$ Publicado no Brasil pela Editora Imaginário. Ver MALATESTA, Errico. A Anarquia. São Paulo: Editora Imaginário, 2001.
} 
perspectiva, a igualdade de condições - ou seja, a propriedade comum dos meios de produção, o socialismo - não é um ponto final, mas o ponto de partida de um processo de evolução social impulsionado por um sentimento de solidariedade entre os seres humanos e realizado pela livre iniciativa de todos. A definição não propõe um modelo estático de uma sociedade perfeita, mas descreve uma sociedade aberta socialista. Ao definir a anarquia em termos de um sentimento, a solidariedade, e de um método, o método da liberdade, Malatesta postula a continuidade entre a ação anarquista no presente e na sociedade futura. E como esse sentimento e esse método são escolhas voluntárias de cada indivíduo, a perspectiva de Malatesta é uma visão gradualista da anarquia, que se materializará na medida em que mais e mais pessoas adotem esse sentimento e esse método. De fato, Malatesta completa sua definição de anarquia: "Não é perfeição, não é o ideal absoluto que, como o horizonte, recua tão rápido quanto nos aproximamos dele; mas é o caminho aberto para todo o progresso e todas as melhorias em benefício de todos". Eu não conseguiria pensar em uma definição mais distante do estereótipo fanático do anarquismo como uma filosofia do "tudo ou nada".

\section{Referências bibliográficas}

LINDEN, Marcel van Der. Globalizando a Historiografia das Classes Trabalhadoras e dos Movimentos Operários: Alguns Pensamentos Preliminares. Revista Trajetos, vol. $1, \mathrm{n}^{\mathrm{o}} 2$ (dez), $\quad 2002.1-14, \quad$ Disponível em: <http://www.revistatrajetos.ufc.br/index.php/Trajetos/article/viewFile/51/26>. Acesso em: 28 jan. 2018.

MALATESTA, Errico. A Anarquia. São Paulo: Editora Imaginário, 2001.

MALATESTA, Errico. Un lavoro lungo e paziente...: Il socialismo anarchico dell'Agitazione, 1897-1898. Opere Complete, vol. 3. Milão/Ragusa: Zero in Condotta/La Fiaccola, 2011.

MALATESTA, Errico. Verso l'Anarchia: Malatesta in America (1899-1900). Opere Complete, vol. 4. Milão/Ragusa: Zero in Condotta/La Fiaccola, 2012.

MALATESTA, Errico. Lo sciopero armato (1900-1913). Opere Complete, vol.5. Milão/Ragusa: Zero in Condotta/La Fiaccola, 2015.

TURCATO, Davide. Making Sense of Anarchism: Errico Malatesta's Experiments with Revolution, 1889-1900. Oakland: AK Press, 2015. 
TURCATO, Davide. Italian Anarchism as a transnational movement, 1885-1915.

International Review of Social History, vol. 52, no 3 (dec.), p. 407-444, 2007. 